\title{
The CERAD Neuropsychological Battery in Patients with Frontotemporal Lobar Degeneration
}

\author{
Ramona M. Haanpääa Noora-Maria Suhonen ${ }^{c, d}$ Päivi Hartikainen ${ }^{b}$ \\ Anne M. Koivisto ${ }^{a}$ b Virpi Moilanen ${ }^{c}$ Sanna-Kaisa Herukka ${ }^{a}{ }^{b}$ \\ Tuomo Hänninen $^{b} \quad$ Anne M. Remes ${ }^{a}$ b

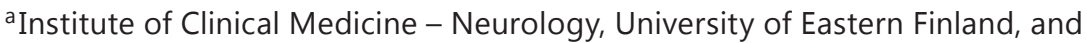 \\ ${ }^{b}$ Department of Neurology, Kuopio University Hospital, Kuopio, and ${ }^{C}$ Department of \\ Neurology, Oulu University Hospital, and ${ }^{~}$ Institute of Clinical Medicine - Neurology, \\ University of Oulu, Oulu, Finland
}

\author{
Key Words \\ Cognition · Frontotemporal dementia - Frontotemporal lobar degeneration · CERAD \\ neuropsychological battery · Trail Making Test · Aphasia
}

\begin{abstract}
Background/Aims: The diagnosis of frontotemporal lobar degeneration (FTLD) is based on neuropsychological examination in addition to clinical symptoms and brain imaging. There is no simple, validated, cognitive tool available in screening for FTLD. The Consortium to Establish a Registry for Alzheimer's Disease neuropsychological battery (CERAD-NB) was originally devised to identify the early cognitive changes related to Alzheimer's disease (AD). Our aim was to investigate the utility of the CERAD-NB in FTLD. Methods: Patients with FTLD $(n=95)$ and AD $(n=90)$ were assessed with the CERAD-NB, Trail Making Test parts $A$ and $B$ and singleletter Phonemic Fluency. Results: FTLD patients were more severely impaired in the Verbal Fluency subtest in the CERAD-NB and Trail Making Test part A compared to AD patients. In addition, $A D$ patients were more impaired in memory subtests compared to FTLD patients. Conclusion: The CERAD-NB may be a useful tool in screening for FTLD. Impaired performance in Verbal Fluency with moderately well-preserved Delayed Recall and Memory Tests may help in identifying patients with probable FTLD and discriminating FTLD from AD. Adding the Trail Making Test to the battery might enhance its value as a screening instrument for FTLD.
\end{abstract}


Frontotemporal Lobar Degeneration

\section{Introduction}

Frontotemporal lobar degeneration (FTLD) is the second most common early-onset dementia after Alzheimer's disease (AD) and can be divided into three major clinical subgroups. The most frequent phenotype is behavioral variant frontotemporal dementia (bvFTD) which is characterized by personality changes, social dysfunction and executive deficits. FTLD also includes two language variants: semantic variant primary progressive aphasia (semantic variant PPA, also known as semantic dementia) and nonfluent/agrammatic variant PPA (or progressive nonfluent afasia). Patients with semantic variant PPA experience difficulties in single-word comprehension, naming and recognizing objects and faces. Typically, their speech is fluent, but empty of content. Nonfluent/agrammatic variant PPA is characterized by effortful speech and agrammatism in language production $[1,2]$.

In the absence of diagnostic biomarkers, the diagnosis of FTLD is based on clinical diagnostic criteria $[1,2]$. However, the clinical heterogeneity of the syndrome makes early diagnosis challenging, and, usually, FTLD patients receive their clinical diagnosis later than AD patients [3]. Neuropsychological assessment is an important tool in the diagnostics of FTLD [4]. However, early detection of dementing diseases requires screening methods that can be easily administered in clinical practice. The Consortium to Establish a Registry for Alzheimer's Disease neuropsychological battery (CERAD-NB) is a relatively brief standardized test battery designed to measure primary cognitive deficits in $\mathrm{AD}$ [5], and it is widely used in the evaluation of cognitive decline and dementia [6]. In Finland, the CERADNB is a commonly used screening tool for detecting mild cognitive impairment and mild AD [7]. However, there is little knowledge of its usefulness for identifying patients with FTLD [8-11].

The aim of the present study was to examine the utility of the CERAD-NB in the early detection of FTLD and in distinguishing FTLD from AD patients, and to determine whether the addition of some executive tests to the battery would enhance its value as a screening instrument for FTLD.

\section{Materials and Methods}

\section{Patients}

The study population consisted of 95 FTLD patients (44 males) diagnosed according to Neary's criteria and 90 AD patients (39 males) diagnosed according to the NINCDS-ADRDA guidelines from two memory outpatient clinics in Finland (Kuopio University and Oulu University Hospitals) during 2000-2014 (table 1). In the FTLD group, 72 patients (75.8 \%) were diagnosed with bvFTD, 14 patients $(14.7 \%)$ with nonfluent/agrammatic variant PPA, 5 patients (5.3\%) with semantic variant PPA and 2 patients with bvFTD and amyotrophic lateral sclerosis. The AD group was gender and Mini-Mental State Examination (MMSE) matched, though the FTLD group was slightly younger and better educated than the AD group (table 1). Patients with previous or current major other neurological or psychiatric disorders, head trauma or other diseases affecting cognition were excluded.

All of the patients were clinically examined by a neurologist specialized in dementia. Structural brain imaging (MRI or CT) was available from all patients. The majority of the patients had also undergone neuropsychological examination during the diagnostic process including tests for executive function, reasoning, visuospatial and verbal performance and memory. Both the Trail Making Test (TMT) and Phonemic Fluency are tests which are used frequently for the evaluation of early dementia but, for various reasons, they were not used 
Table 1. Demographics of FTLD and AD patients

\begin{tabular}{lcrr}
\hline & FTLD & AD & p value \\
\hline Males & $44(46 \%)$ & $39(43 \%)$ & 0.684 \\
Age at the time of CERAD-NB, years & $68.0 \pm 8.4(48-89)$ & $72.3 \pm 7.7(50-85)$ & $\leq 0.001$ \\
Education, years & $9.6 \pm 3.5(6-17)$ & $9.1 \pm 3.7(6-18)$ & 0.214 \\
\hline
\end{tabular}

Data are the mean \pm SD with ranges in parentheses, unless otherwise indicated.

for all patients. Detailed neuropsychological data were available in 93\% of the FTLD patients ( $\mathrm{n}=88$ ). The CERAD-NB was performed during the diagnostic process. The Ethics Committees of Kuopio and Oulu University Hospital approved the study.

\section{Finnish Version of the CERAD-NB}

The Finnish version of the CERAD-NB [12,13] includes 9 subtests: Verbal Fluency (animals in $60 \mathrm{~s}$ ), 15-item Boston Naming Test, MMSE, Word List Learning, Word List Recall and Word List Recognition, Constructional Praxis, Delayed Constructional Praxis and Clock Drawing. We also calculated some of the compound scores such as the CERAD-NB Total Score [14], Total Recall, Memory Index and Memory Total Score [15].

Word List Delayed Recall Savings is the percentage of words in the delayed recall as compared to the third learning trial, whereas Constructional Praxis Savings is the percentage of the figures on the Delayed Recall compared to the figures copied in the Constructional Praxis subtest. Total Recall combines Word List Delayed Recall and Word List Recognition scores [7]. The CERAD-NB Total Score is the sum score from every subtest excluding MMSE. The Total Score calculates the Word List Recognition as discriminability where false-positive recognitions are subtracted from the correct ones [14]. The Memory Total Score summates the subtests of Word List Recall, Word List Recognition (correct positives + correct negative recognitions) and Constructional Praxis Recall, and it has a maximum score of 41 . The Memory Index is the mean percentage of Word List Delayed Recall Savings, Word List Recognition \% (based on discriminability) and Constructional Praxis Savings [15]. The Finnish cutoff values are based on normative data and are intended to facilitate the screening of mild cognitive impairment and dementia in primary health care $[7,16]$.

\section{Other Cognitive Tests}

In addition to CERAD-NB, we collected the results of two widely used cognitive tests that evaluate executive functions [17]: TMT parts A and B [18] and a short version of the Controlled Oral Word Association Test [19] using single-letter Phonemic Fluency. The result of the TMT is given as the time in seconds needed to complete the task. The maximum time for TMT part A is $150 \mathrm{~s}$ and for TMT part B $300 \mathrm{~s}$. In the Phonemic Fluency test, patients are required to name as many words as possible beginning with a certain letter. In this study, letters $\mathrm{P}$ and $\mathrm{S}$ were used because words beginning with these letters are approximately equally common in the Finnish language. The score in this test is the number of words generated by the patient in $1 \mathrm{~min}$ for each letter at a time.

The CERAD-NB profile was also analyzed in the group of patients with an MMSE score $\geq 24$ to evaluate the profile in a possibly mild stage of the disease and also in the subgroup of patients with the nonfluent/agrammatic variant PPA phenotype. The analyses were not performed in patients with semantic variant PPA because of the small sample size $(n=5)$. 
Haanpää et al.: The CERAD Neuropsychological Battery in Patients with

Frontotemporal Lobar Degeneration

Table 2. CERAD-NB subtests with maximum scores, mean scores, standard deviations, minimum and maximum scores for FTLD and $\mathrm{AD}$ groups and group-wise comparisons of the differences

\begin{tabular}{|c|c|c|c|c|c|c|c|}
\hline $\begin{array}{l}\text { CERAD-NB subtest } \\
\text { (maximum score) }\end{array}$ & $\begin{array}{l}\text { FTLD, } \\
\text { mean } \pm \text { SD (range) }\end{array}$ & $\mathrm{n}$ & $\begin{array}{l}\mathrm{AD} \\
\text { mean } \pm \mathrm{SD} \text { (range) }\end{array}$ & $\mathrm{n}$ & $\begin{array}{l}\text { t value }^{1} \\
\text { (d.f.) }\end{array}$ & $\begin{array}{l}\mathrm{p} \\
\text { (2-tailed) }\end{array}$ & $\begin{array}{l}\text { Cohen's } \\
\text { d value }^{1}\end{array}$ \\
\hline Verbal Fluency (animals) & $11.8 \pm 5.6(1-25)$ & 89 & $14.0 \pm 5.7(2-26)$ & 90 & & $0.005^{1}$ & \\
\hline Boston Naming Test (15) & $9.9 \pm 3.5(1-15)$ & 88 & $10.5 \pm 3.1(1-15)$ & 90 & $1.15(176)$ & 0.251 & -0.173 \\
\hline MMSE (30) & $22.6 \pm 4.5(9-30)$ & 93 & $22.7 \pm 4.0(8-30)$ & 88 & $0.11(179)$ & 0.913 & -0.016 \\
\hline Word List Learning (30) & $13.5 \pm 5.7(0-27)$ & 94 & $13.8 \pm 4.9(0-26)$ & 90 & & $0.929^{1}$ & \\
\hline Constructional Praxis (11) & $8.7 \pm 2.2(2-11)$ & 79 & $8.7 \pm 2.1(4-11)$ & 89 & $0.15(166)$ & 0.880 & -0.024 \\
\hline Word List Delayed Recall (10) & $3.6 \pm 2.2(0-10)$ & 93 & $2.5 \pm 2.0(0-8)$ & 89 & $-3.53(180)$ & 0.001 & 0.524 \\
\hline Word List Delayed Recall Savings, \% (100) & $61.6 \pm 28.7(0-100)$ & 91 & $42.7 \pm 30.8(0-100)$ & 88 & $-4.25(177)$ & $\leq 0.001$ & 0.634 \\
\hline Word List Recognition (20) & $16.5 \pm 3.3(1-20)$ & 87 & $16.1 \pm 2.7(8-20)$ & 90 & $-0.84(175)$ & 0.400 & 0.126 \\
\hline Word List Discriminability (10) & $6.6 \pm 3.0(0-10)$ & 80 & $6.1 \pm 2.7(0-10)$ & 88 & $-1.23(166)$ & 0.222 & 0.189 \\
\hline Word List Recognition, \% (100) & $82.4 \pm 16.6(5-100)$ & 87 & $80.5 \pm 13.5(40-100)$ & 90 & $-0.84(175)$ & 0.400 & 0.127 \\
\hline Total Recall (30) & $20.1 \pm 5.1(1-30)$ & 86 & $18.6 \pm 4.1(8-28)$ & 89 & & $0.010^{1}$ & \\
\hline Constructional Praxis: Delayed Recall (11) & $5.6 \pm 3.3(0-11)$ & 77 & $3.9 \pm 3.2(0-11)$ & 89 & $-3.32(164)$ & 0.001 & 0.515 \\
\hline Constructional Praxis: Savings, \% (100) & $61.0 \pm 33.0(0-100)$ & 77 & $43.9 \pm 34.5(0-100)$ & 89 & $-3.25(164)$ & 0.001 & 0.506 \\
\hline Clock Drawing (6) & $3.5 \pm 2.0(0-6)$ & 91 & $3.7 \pm 2.1(0-6)$ & 90 & 0.86 (179) & 0.391 & -0.127 \\
\hline Memory Total Score (41) & $25.5 \pm 7.4(1-39)$ & 72 & $22.5 \pm 6.3(10-39)$ & 88 & & $0.003^{1}$ & \\
\hline Memory Index, \% (100) & $63.3 \pm 23.6(0-100)$ & 67 & $49.9 \pm 22.4(0-93)$ & 86 & & $0.001^{1}$ & \\
\hline Total Score (100) & $54.1 \pm 16.8(14-92)$ & 68 & $55.5 \pm 14.9(15-95)$ & 88 & & $0.658^{1}$ & \\
\hline
\end{tabular}

${ }^{1}$ The $t$ test was not appropriate. The Mann-Whitney U test was used because values were not normally distributed.

\section{Statistical Analysis}

Means, standard deviations, minimum and maximum values of every CERAD-NB subtest were calculated both from the groups of FTLD and AD patients. The Kolmogorov-Smirnov and Shapiro-Wilk tests were used to evaluate the normal distribution of all CERAD-NB subtest scores. The independent-samples $t$ test was used with normally distributed parameters, while the subtests of Verbal Fluency, Word List Learning and the compound scores of Total Recall, Total Score, Memory Total Score and Memory Index proved to be non-normally distributed, and, hence, the Mann-Whitney U test was used. The effect size estimator Cohen's $\mathrm{d}$ value was calculated for normally distributed parameters to describe the magnitude of the group's differences in subtests and compound scores. Values between 0.20 and 0.50 are considered to have only a small effect, values of $0.50-0.80$ a medium effect and values $>0.80$ a large effect. The $\chi^{2}$ test was used to compare the number of scores below the Finnish cutoff values in the FTLD and AD groups. A p value $<0.05$ was considered statistically significant throughout the whole study. The savings values of the CERAD-NB subtests that exceeded $100 \%$ were reduced to a value of $100 \%$ in all of the analyses. The value management and all the statistical analyses were conducted using IBM Statistics SPSS 21.

\section{Results}

Patients with FTLD were more frequently impaired in the Verbal Fluency subtest (animals) compared to the AD group ( $\mathrm{p} \leq 0.05$; tables 2,3 ). In contrast, performance in the Word List Delayed Recall and Constructional Praxis Delayed Recall subtests and the compound scores of the Memory Total Score and Memory Index were better in the FTLD group compared to the AD group. In the subtests of Word List Delayed Recall and Savings as well as of Constructional Praxis Delayed Recall and Savings, the magnitude of the effect size was medium according to Cohen's d value. There were no significant differences between FTLD 
Table 3. Percentages below cutoff scores in every subtest in the FTLD and AD groups and group-wise comparisons of the differences

\begin{tabular}{lcccc}
\hline Subtest of CERAD-NB & FTLD & AD & $\begin{array}{c}\chi^{2} \text { value } \\
\text { (d.f. }=1)\end{array}$ & $\begin{array}{l}\text { p } \\
\text { (2-sided) }\end{array}$ \\
\hline Verbal Fluency (animals) & & & 6.789 & 0.009 \\
Boston Naming Test & 74.2 & 55.6 & 0.901 & 0.342 \\
MMSE & 63.6 & 56.7 & 0.940 & 0.332 \\
Word List Learning (sum score) & 61.3 & 68.2 & 0.636 & 0.425 \\
Word List Delayed Recall & 69.1 & 74.4 & 6.323 & 0.012 \\
Word List Delayed Recall Savings (\%) & 65.6 & 82.0 & 13.826 & $\leq 0.001$ \\
Word List Recognition (\%) & 60.4 & 85.2 & 2.444 & 0.118 \\
Total Recall & 52.9 & 64.4 & 3.512 & 0.061 \\
Constructional Praxis: Savings (\%) & 68.6 & 80.9 & 11.383 & 0.001 \\
Clock Drawing & 39.0 & 65.2 & 1.627 & 0.202
\end{tabular}

Table 4. Results of the TMT part A and the Word Fluency test with letters P and S in the FTLD and AD groups

\begin{tabular}{|c|c|c|c|c|c|c|c|c|c|c|}
\hline & FTLD & $\mathrm{n}$ & $\mathrm{AD}$ & $\mathrm{n}$ & $\begin{array}{l}\mathrm{p} \\
\text { (2-tailed) }\end{array}$ & $\begin{array}{l}\text { Nonfluent/agrammatic } \\
\text { variant PPA }\end{array}$ & $\mathrm{n}$ & bvFTD & $\mathrm{n}$ & $\begin{array}{l}\mathrm{p} \\
\text { (2-tailed) }\end{array}$ \\
\hline TMT-A & $99.03 \pm 38.8(9-150)$ & 63 & $79.55 \pm 33.2(30-150)$ & 47 & 0.004 & $110.11 \pm 40.7(62-150)$ & 9 & $97.27 \pm 38.9(9-150)$ & 51 & 0.415 \\
\hline TMT-B & $240.87 \pm 77.9(74-300)$ & 31 & $243.11 \pm 63.47(156-300)$ & 19 & 0.948 & $282.00 \pm 40.2(210-300)$ & 5 & $240.57 \pm 79.2(74-300)$ & 21 & 0.308 \\
\hline Fluency (P) & $4.95 \pm 3.81(0-11)$ & 21 & $9.11 \pm 4.6(3-18)$ & 18 & 0.009 & $6.00 \pm 4.2(2-11)$ & 4 & $4.88 \pm 2.8(0-11)$ & 16 & 0.682 \\
\hline Fluency (S) & $6.73 \pm 4.9(0-21)$ & 44 & $11.68 \pm 4.6(4-19)$ & 19 & $\leq 0.001$ & $5.90 \pm 4.0(0-12)$ & 10 & $7.29 \pm 5.1(0-21)$ & 31 & 0.622 \\
\hline
\end{tabular}

Data are given as the mean \pm SD with ranges in parentheses. The Mann-Whitney $U$ test was used for the group-wise comparison of differences.

and AD groups in their performance in the MMSE or in the subtest of Constructional Praxis, Word List Learning, Word List Recognition or Clock Drawing tests.

The FTLD group performed significantly less well in the Phonemic Fluency test $(p=0.009$ and $\mathrm{p} \leq 0.001$; table 4$)$ and TMT part A $(\mathrm{p}=0.004)$ compared to the AD group. There was no difference between the groups in the TMT part B. However, only $45.2 \%$ of patients in the FTLD group and $52.6 \%$ in the AD group were able to complete the TMT part B within the time limit of $300 \mathrm{~s}$.

When focusing on patients with an MMSE score $\geq 24$, patients with FTLD were also the most impaired in the subtests of Verbal Fluency and Boston Naming Test; however, there was no significant difference compared to AD (table 5). Instead, the FTLD group performed better in the subtests of Word List and Constructional Praxis Delayed Recall and also in the compound scores of Total Recall, Memory Total Score and Memory Index compared to the AD group.

The CERAD-NB profile was rather similar in patients with nonfluent/agrammatic variant PPA compared to the whole FTLD group (table 6). Patients with nonfluent/agrammatic variant PPA performed better in the Memory Index, Constructional Praxis Delayed Recall and Savings tests as compared to the AD group.

\section{Discussion}

We found that the FTLD patients were more impaired on the CERAD-NB subtest of Verbal Fluency (animals) than patients with AD. Two thirds of FTLD patients performed below the Finnish cutoff value in this test. A similar finding was detected in the Phonemic Fluency test. A decline in verbal and phonemic fluency is associated with executive dysfunction and a 
Haanpää et al.: The CERAD Neuropsychological Battery in Patients with

Frontotemporal Lobar Degeneration

Table 5. Patients with an MMSE score $\geq 24$ : CERAD-NB subtests with maximum scores, mean scores, standard deviations, minimum and maximum scores for FTLD and AD groups and group-wise comparisons of the differences

\begin{tabular}{|c|c|c|c|c|c|c|c|}
\hline $\begin{array}{l}\text { CERAD-NB subtest } \\
\text { (maximum score) }\end{array}$ & $\begin{array}{l}\text { FTLD, } \\
\text { mean } \pm \text { SD (range) }\end{array}$ & $\mathrm{n}$ & $\begin{array}{l}\mathrm{AD} \\
\text { mean } \pm \mathrm{SD} \text { (range) }\end{array}$ & $\mathrm{n}$ & $\mathrm{t}$ value & $\begin{array}{l}\mathrm{p} \\
\text { (2-tailed) }\end{array}$ & $\begin{array}{l}\text { Cohen's } \\
\text { d value }\end{array}$ \\
\hline Verbal Fluency (animals) & $14.2 \pm 5.1(5-25)$ & 42 & $15.5 \pm 4.6(7-26)$ & 40 & & $0.209^{2}$ & \\
\hline Boston Naming Test (15) & $10.7 \pm 3.8(1-15)$ & 42 & $11.6 \pm 2.3(7-15)$ & 40 & $1.35(67)^{1}$ & 0.183 & -0.297 \\
\hline MMSE (30) & $26.4 \pm 1.7(24-30)$ & 43 & $25.9 \pm 1.6(24-30)$ & 40 & $-1.36(81)$ & 0.179 & 0.303 \\
\hline Word List Learning (30) & $16.6 \pm 4.5(7-27)$ & 43 & $15.7 \pm 4.3(8-26)$ & 40 & & $0.313^{2}$ & \\
\hline Constructional Praxis (11) & $9.4 \pm 1.5(6-11)$ & 39 & $9.4 \pm 1.8(5-11)$ & 39 & $0.07(76)$ & 0.947 & -0.018 \\
\hline Word List Delayed Recall (10) & $4.9 \pm 1.9(1-10)$ & 43 & $3.2 \pm 2.1(0-8)$ & 39 & $-3.83(80)$ & $\leq 0.001$ & 0.669 \\
\hline Word List Delayed Recall Savings, \% (100) & $71.7 \pm 22.7(17-100)$ & 43 & $48.8 \pm 27.8(0-100)$ & 39 & $-4.11(80)$ & $\leq 0.001$ & 0.903 \\
\hline Word List Recognition (20) & $17.7 \pm 2.4(11-20)$ & 41 & $17.1 \pm 2.1(12-20)$ & 40 & $-1.26(79)$ & 0.212 & 0.279 \\
\hline Word List Discriminability (10) & $7.8 \pm 2.4(1-10)$ & 40 & $7.1 \pm 2.1(0-10)$ & 38 & $-1.29(76)$ & 0.200 & 0.294 \\
\hline Word List Recognition, \% (100) & $88.7 \pm 12.0(55-100)$ & 41 & $85.5 \pm 10.5(60-100)$ & 40 & $-1.26(79)$ & 0.212 & 0.280 \\
\hline Total Recall (30) & $22.7 \pm 3.8(12-30)$ & 41 & $20.2 \pm 3.4(15-28)$ & 39 & & $0.002^{2}$ & \\
\hline Constructional Praxis: Delayed Recall (11) & $7.1 \pm 2.6(0-11)$ & 39 & $4.8 \pm 3.7(0-11)$ & 39 & $-3.19(68)^{1}$ & 0.002 & 0.725 \\
\hline Constructional Praxis: Savings, \% (100) & $74.8 \pm 24.7(0-100)$ & 39 & $50.6 \pm 37.4(0-100)$ & 39 & $-3.37(66)^{1}$ & 0.001 & 0.764 \\
\hline Clock Drawing (6) & $4.2 \pm 1.8(1-6)$ & 41 & $4.4 \pm 1.9(0-6)$ & 40 & $0.38(79)$ & 0.708 & -0.086 \\
\hline Memory Total Score (41) & $29.7 \pm 4.9(17-39)$ & 37 & $25.1 \pm 5.8(16-39)$ & 38 & & $0.001^{2}$ & \\
\hline Memory Index, \% (100) & $74.3 \pm 16.4(24-100)$ & 36 & $57.8 \pm 20.1(20-93)$ & 37 & & $0.001^{2}$ & \\
\hline Total Score $(100)$ & $63.4 \pm 12.5(35-92)$ & 37 & $62.4 \pm 11.2(41-95)$ & 38 & & $0.468^{2}$ & \\
\hline
\end{tabular}

${ }^{1}$ The $t$ test was used for unequal variances, with a Levene's test significance level of $\leq 0.05$.

2 The Mann-Whitney U test was used because values were not normally distributed.

Table 6. CERAD-NB scores of patients with nonfluent/agrammatic variant PPA: mean scores, standard deviations, minimum and maximum scores for nonfluent/agrammatic variant PPA and AD groups and group-wise comparisons of the differences with the Mann-Whitney U test

\begin{tabular}{|c|c|c|c|c|c|}
\hline $\begin{array}{l}\text { CERAD-NB subtest } \\
\text { (maximum score) }\end{array}$ & $\begin{array}{l}\text { Nonfluent/agrammatic variant } \\
\text { PPA, mean } \pm \text { SD (range) }\end{array}$ & $\mathrm{n}$ & $\begin{array}{l}\mathrm{AD}, \\
\text { mean } \pm \mathrm{SD} \text { (range) }\end{array}$ & $\mathrm{n}$ & $\begin{array}{l}\mathrm{p} \\
(2 \text {-tailed })\end{array}$ \\
\hline Verbal Fluency (animals) & $11.2 \pm 6.1(4-23)$ & 14 & $14.0 \pm 5.7(2-26)$ & 90 & 0.089 \\
\hline Boston Naming Test (15) & $9.2 \pm 3.4(2-15)$ & 14 & $10.5 \pm 3.1(1-15)$ & 90 & 0.168 \\
\hline MMSE (30) & $22.7 \pm 3.1(9-28)$ & 14 & $22.7 \pm 4.0(8-30)$ & 88 & 0.664 \\
\hline Word List Learning (30) & $12.1 \pm 5.1(0-20)$ & 14 & $13.8 \pm 4.9(0-26)$ & 90 & 0.325 \\
\hline Constructional Praxis (11) & $8.6 \pm 2.7(2-11)$ & 13 & $8.7 \pm 2.1(4-11)$ & 89 & 0.930 \\
\hline Word List Delayed Recall (10) & $3.7 \pm 1.8(0-6)$ & 14 & $2.5 \pm 2.0(0-8)$ & 89 & 0.269 \\
\hline Word List Delayed Recall Savings, \% (100) & $58.3 \pm 22.5(0-86)$ & 13 & $42.7 \pm 30.8(0-100)$ & 88 & 0.066 \\
\hline Word List Recognition (20) & $16.8 \pm 2.8(11-20)$ & 13 & $16.1 \pm 2.7(8-20)$ & 90 & 0.379 \\
\hline Word List Discriminability (10) & $6.8 \pm 2.8(1-10)$ & 13 & $6.1 \pm 2.7(0-10)$ & 88 & 0.361 \\
\hline Word List Recognition, \% (100) & $83.8 \pm 13.9(55-100)$ & 13 & $80.5 \pm 13.5(40-100)$ & 90 & 0.379 \\
\hline Total Recall (30) & $19.9 \pm 3.8(15-26)$ & 13 & $18.6 \pm 4.1(8-28)$ & 89 & 0.321 \\
\hline Constructional Praxis: Delayed Recall (11) & $6.7 \pm 3.6(0-11)$ & 12 & $3.9 \pm 3.2(0-11)$ & 89 & 0.013 \\
\hline Constructional Praxis: Savings, \% (100) & $73.6 \pm 30.1(0-100)$ & 12 & $43.9 \pm 34.5(0-100)$ & 89 & 0.007 \\
\hline Clock Drawing (6) & $3.5 \pm 2.1(1-6)$ & 13 & $3.7 \pm 2.1(0-6)$ & 90 & 0.714 \\
\hline Memory Total Score (41) & $26.2 \pm 6.2(17-37)$ & 12 & $22.5 \pm 6.3(10-39)$ & 88 & 0.095 \\
\hline Memory Index, \% (100) & $67.1 \pm 17.9(30-95)$ & 11 & $49.9 \pm 22.4(0-93)$ & 86 & 0.027 \\
\hline Total Score (100) & $49.3 \pm 15.6(29-79)$ & 12 & $55.5 \pm 14.9(15-95)$ & 88 & 0.126 \\
\hline
\end{tabular}

decline in cognitive flexibility, which are typical features of FTLD. There are only two previous studies comparing patients with FTLD and AD using the CERAD-NB [9, 10]. Diehl et al. [9] also found that patients with bvFTD were more severely impaired in the subtest of Verbal Fluency and patients with semantic variant PPA both in Verbal Fluency and Boston Naming subtests but not in other parts of the CERAD-NB when compared to AD patients. In another study, 
Haanpää et al.: The CERAD Neuropsychological Battery in Patients with

Frontotemporal Lobar Degeneration

Diehl and Kurz [10] found that AD patients were performing significantly less well in Word List Learning, Delayed Recall and Visuoconstruction but found no differences in other subtests compared to FTLD patients. However, Mendez et al. [11] discovered that FTLD patients performed better in the visuospatial constructions and less well in the Boston Naming Test compared to non-FTD patients. In their study, they noticed that neuropsychological measures lacked sensitivity for bvFTD. Kundermann et al. [20] compared FTLD and AD patients' CERAD-NB scores, but their study only consisted of 6 FTLD patients and focused on sleep abnormalities.

We also included executive, frontal function and psychomotor speed tests (TMT parts A and B as well as Phonemic Fluency tests) in our study. Patients with FTLD were severely impaired in all these tests, and there were significant differences between the FTLD and AD groups. TMT part B was problematic for both FTLD and AD groups, and many of the patients were not able to complete the task within the allowed time limit. Executive dysfunction is known to be a characteristic feature of FTLD [2], and defects in e.g. phonemic fluency are a typical finding in this patient group [21-23].

We found that the patients with AD were more severely impaired in all subtests of recall, both in the entire study groups and in the early stage of the disease (MMSE $\geq 24$ ). This type of cognitive profile has been shown to be a typical characteristic of AD patients [7,24]. Sotaniemi et al. [7] indicated that the CERAD-NB was useful in differentiating mild AD cases from cognitively normal elderly individuals with the differentiation most apparent in the following CERAD-NB subtests: Word List Delayed Recall and Savings, Word List Learning and Word List Recognition and also the compound score of Total Recall.

The advantage of our study, compared to previous studies [8-10, 20], is the large sample size. One limitation in our study concerns the identification of the mild stage of FTLD. We used as our cutoff value an MMSE score of 24. However, MMSE is not considered to be a very accurate measure of cognitive decline in FTLD patients.

In conclusion, the FTLD patients performed less well in the Word Fluency test compared to the AD patients, and the majority of FTLD patients performed below the Finnish cutoff value in this test. Furthermore, FTLD patients performed relatively well in the subtests of recall (Word List Delayed Recall and Savings, Constructional Praxis Delayed Recall and Savings and the compound scores of Total Recall, Memory Index and Memory Total Score) compared to AD patients. It seems that adding some executive tests, such as the TMT or Phonemic Fluency test, to the battery might enhance the value of CERAD-NB as a screening instrument for FTLD. Despite the relatively consistent impairment in Verbal Fluency, this profile in CERAD-NB cannot be considered as a specific diagnostic marker for FTLD. Similar impairments in executive functions and fluency may also be found in patients with vascular cognitive impairment and in other diseases affecting the frontal-subcortical circuits $[25,26]$, and the diagnosis of FTLD should be based on a more comprehensive neuropsychological assessment together with brain imaging.

\section{Acknowledgment}

This work was supported in part by EVO grants from the Kuopio University Hospital.

\section{Disclosure Statement}

The authors disclose no conflicts of interest. 
Haanpää et al.: The CERAD Neuropsychological Battery in Patients with

Frontotemporal Lobar Degeneration

\section{References}

1 Gorno-Tempini ML, Hillis AE, Weintraub S, et al: Classification of primary progressive aphasia and its variants. Neurology 2011;76:1006-1014.

-2 Rascovsky K, Hodges JR, Knopman D, et al: Sensitivity of revised criteria for the behavioural variant of frontotemporal dementia. Brain 2011;134:2456-2477.

-3 Rosness TA, Haugen PK, Passant U, Engedal K: Frontotemporal dementia - a clinically complex diagnosis. Int J Geriatr Psychiatry 2008;23:837-842.

4 Bozoki AC, Farooq MU: Frontotemporal lobar degeneration: insights from neuropsychology and neuroimaging. Int Rev Neurobiol 2009;84:185-213.

5 Morris JC, Heyman A, Mohs RC, Hughes JP, van Belle G, Fillenbaum G, Mellits ED, Clark C: The Consortium to Establish a Registry for Alzheimer's Disease (CERAD). Part I. Clinical and neuropsychological assessment of Alzheimer's disease. Neurology 1989;39:1159-1165.

6 Fillenbaum GG, van Belle G, Morris JC, et al: Consortium to Establish a Registry for Alzheimer's Disease (CERAD): the first twenty years. Alzheimers Dement 2008;4:96-109.

7 Sotaniemi M, Pulliainen V, Hokkanen L, Pirttilä T, Hallikainen I, Soininen H, Hänninen T: CERAD-neuropsychological battery in screening mild Alzheimer's disease. Acta Neurol Scand 2012;125:16-23.

8 Diehl-Schmid J, Bornschein S, Pohl C, Förstl H, Kurz A, Jahn T: Cognitive decline in the behavioral variant of frontotemporal dementia. Int Psychogeriatr 2011;23:230-237.

-9 Diehl J, Monsch AU, Aebi C, Wagenpfeil S, Krapp S, Grimmer T, Seeley W, Förstl H, Kurz A: Frontotemporal dementia, semantic dementia, and Alzheimer's disease: the contribution of standard neuropsychological tests to differential diagnosis. J Geriatr Psychiatry Neurol 2005;18:39-44.

10 Diehl J, Kurz A: Frontotemporal dementia: patient characteristics, cognition, and behaviour. Int J Geriatr Psychiatry 2002;17:914-918.

11 Mendez MF, Shapira JS, McMurtray A, Licht E, Miller BL: Accuracy of the clinical evaluation for frontotemporal dementia. Arch Neurol 2007;64:830-835.

12 Hänninen T, Veijo Pulliainen V, Salo J, Hokkanen L, Erkinjuntti T, Koivisto K, Viramo P, Soininen H: Suomen muistitutkimusyksiköiden asiantuntijaryhmä. Kognitiiviset testit muistihäiriöiden ja alkavan dementian varhaisdiagnostiikassa: CERAD-tehtäväsarja. Suomen Lääkärilehti 1999;15:1967-1975.

13 Pulliainen V, Hokkanen L, Salo J, Hänninen T: CERAD-kognitiivinen tehtäväsarja. Käsikirja. [Manual of the Finnish version of the CERAD]. Kuopio, Suomen Alzheimertutkimusseura ry, 1999.

14 Chandler MJ, Lacritz LH, Hynan LS, Barnard HD, Allen G, Deschner M, Weiner MF, Cullum CM: A total score for the CERAD neuropsychological battery. Neurology 2005;65:102-106.

15 Paajanen T, Hänninen T, Tunnard C, Hallikainen M, Mecocci P, Sobow T, Tsolaki M, Vellas B, Lovestone S, Soininen H: CERAD neuropsychological compound scores are accurate in detecting prodromal Alzheimer's disease: a prospective AddNeuroMed study. J Alzheimers Dis 2014;39:679-690.

16 Pulliainen V, Hänninen T, Hokkanen L, Tervo S, Vanhanen M, Pirttilä T, Soininen H: Muistihäiriöiden seulonta - suomalaiset normit CERAD-tehtäväsarjalle. Suomen Lääkärilehti 2007;62:1235-1241.

17 Schmid NS, Ehrensperger MM, Berres M, Beck IR, Monsch AU: The extension of the German CERAD neuropsychological assessment battery with tests assessing subcortical, executive and frontal functions improves accuracy in dementia diagnosis. Dement Geriatr Cogn Dis Extra 2014;4:322-334.

18 Reitan R: Validity of the Trail-Making Test as an indication of organic brain damage. Percept Mot Skills 1958; 8:271-276.

19 Benton AL, de Hamsher SK, Sivan AB: Multilingual Aplasia Examination, ed 2. Iowa City, AJA Associates, 1983.

20 Kundermann B, Thum A, Rocamora R, Haag A, Krieg JC, Hemmeter U: Comparison of polysomnographic variables and their relationship to cognitive impairment in patients with Alzheimer's disease and frontotemporal dementia. J Psychiatr Res 2011;45:1585-1592.

-21 Perri R, Koch G, Carlesimo GA, Serra L, Fadda L, Pasqualetti P, Pettenati C, Caltagirone C: Alzheimer's disease and frontal variant of frontotemporal dementia - a very brief battery for cognitive and behavioural distinction. J Neurol 2005;252:1238-1244.

22 Siri S, Benaglio I, Frigerio A, et al: A brief neuropsychological assessment for the differential diagnosis between frontotemporal dementia and Alzheimer's disease. Eur J Neurol 2001;8:125-132.

-23 Yoshizawa H, Vonsattel JP, Honig LS: Presenting neuropsychological testing profile of autopsy-confirmed frontotemporal lobar degeneration. Dement Geriatr Cogn Disord 2013;36:279-289.

24 Perry R, Hodges J: Differentiating frontal and temporal variant frontotemporal dementia from Alzheimer's disease. Neurology 2000;52:2277-2284.

25 Jokinen H, Kalska H, Ylikoski R, Madureira S, Verdelho A, van der Flier WM, Scheltens P, Barkhof F, Visser MC, Fazekas F, Schmidt R, O’Brien J, Waldemar G, Wallin A, Chabriat H, Pantoni L, Inzitari D, Erkinjuntti T; LADIS group: Longitudinal cognitive decline in subcortical ischemic vascular disease - the LADIS Study. Cerebrovasc Dis 2009;27:384-391.

-26 Ramos-Estébanez C, Moral-Arce I, Muñoz-Arrondo R, González-Mandly A, Matorras-Galán P, González-Macias J, Hernández-Hernández JL: Vascular cognitive impairment: prodromal stages of ischemic vascular dementia. Dement Geriatr Cogn Disord 2008;25:451-460. 